\title{
Novel triazole analogs of apigenin-7-methyl ether exhibit potent antitumor activity against ovarian carcinoma cells via the induction of mitochondrial-mediated apoptosis
}

\author{
YUYAN QI ${ }^{1}$, ZHAOXIA DING $^{1}$, YUSHUANG YAO ${ }^{1}$, DEHUA MA ${ }^{1}$, \\ FEIFEI REN ${ }^{2}$, HONGJUAN YANG ${ }^{1}$ and AIPING CHEN ${ }^{1}$ \\ ${ }^{1}$ Department of Gynecology, The Affiliated Hospital of Qingdao University, \\ Qingdao, Shandong 266000; ${ }^{2}$ Department of Obstetrics and Gynecology, \\ The Affiliated Hospital of Taishan Medical University, Taian, Shandong 271000, P.R. China
}

Received October 26, 2017; Accepted July 13, 2018

DOI: 10.3892/etm.2018.7138

\begin{abstract}
Ovarian cancer is one of the main causes of cancer-associated mortality across the world. Currently, ovarian cancer is mainly treated with chemotherapy. However, ovarian cancer is detected at advanced stages and chemotherapy has numerous side effects. In addition, the results of current chemotherapy on the treatment of ovarian cancer are less than satisfactory. Therefore, there is an urgent need to develop novel and more viable chemotherapeutic agents that can be used to treat ovarian cancer. The present study was designed to synthesize a series of novel triazole analogs of the bioactive apigenin-7-methyl ether to evaluate its anticancer activity against three human ovarian cancer cell lines. A total of eight novel triazole derivatives were synthesized and screened for their anticancer activity. Of all the derivatives, a derivative named 3d exhibited significant and dose-dependent anticancer activity against the SKOV3 ovarian cancer cell line. The $\mathrm{IC}_{50}$ of $3 \mathrm{~d}$ was found to be $10 \mu \mathrm{M}$ against the SKOV3 cancer cell line. It was also observed that $3 \mathrm{~d}$ induced apoptosis in SKOV3 cancer cells through the accretion of reactive oxygen species and reduction in mitochondrial membrane potential. The molecule also modulated the expression of B-cell lymphoma 2 (Bcl-2) and Bcl-2-associated X protein. Taken together, these results showed that the apigenein-7-methyl ether novel derivative $3 \mathrm{~d}$ may prove an important lead molecule for the treatment of ovarian cancer.
\end{abstract}

Correspondence to: Dr Aiping Chen, Department of Gynecology, The Affiliated Hospital of Qingdao University, 16 Jiangsu Road, Shinan, Qingdao, Shandong 266000, P.R. China

E-mail: aipingchen9@hotmail.com

Key words: apigenein-7-methyl ether, ovarian cancer, apoptosis, reactive oxygen species

\section{Introduction}

Ovarian cancer remains of the main causes of cancer-associated mortality. Ovarian cancer is mainly treated by chemotherapy and/or by surgical interventions $(1,2)$. Although, the initial responses to chemotherapy are encouraging, the tumors often reoccur. Additionally, only limited anticancer agents are available for the treatment of ovarian cancer $(3,4)$. Naturally occurring compounds have gained considerable attention for the prevention of various types of cancer (5-7). Flavonoids consist of a large group of polyphenolics having a benzo- $\gamma$-pyrone skeleton and are widely distributed in the plant kingdom (8) These are also frequently found in fruits, grains, green tea and other dietary supplements $(9,10)$. Numerous biological activities have been reported for flavonoids, including antioxidant, antitumor, anti-inflammatory, antiallergenic and hepatoprotective activities $(11,12)$. It has been found that a flavonoid rich diet reduces the risk of chronic diseases, particularly cancer, including prostate and breast cancer, indicating their potential role as anticancer agents $(13,14)$. Flavonoids, including flavopiridol, epigallocatechin gallate and quercetin, have emerged as potent anticancer drug candidates and a number of these have already entered clinical trials (15).

Apeginin-7-methyl ether is a naturally occurring flavonoid known to possess several pharmacological properties, including anti-inflammatory, antioxidant, and cytotoxic properties (16). Among these, its anticancer effect has been reported against various human cancer cells (16). These findings suggest that apigenin is an ideal bioactive scaffold for the synthesis of a series of analogues and examination of their structure-activity associations, and justify its further investigation. In this context, the present study targeted apeginin-7-methyl ether to synthesize 1,2,3-triazole analogs. Heterocyclic moieties, including 1,2,3-triazoles, are frequently occurring structural motifs in various pharmaceuticals, and are reported to exhibit diverse biological activities, including anti-human immunodeficiency virus (17), antimicrobial (18) and anticancer effects $(19,20)$. The addition of such heterocyclic groups can influence the effectiveness, polarity and aqueous solubility of the parent compound $(21,22)$. Furthermore, triazoles are stable against 
acidic and basic hydrolysis, which is advantageous in resisting metabolic degradation (23). These also have a high dipole moment to facilitate hydrogen bond formation and dipole-dipole interactions while interacting with membrane proteins $(24,25)$.

In view of the preceding discussion, the present study introduced a triazole moiety at the $4^{\prime}-\mathrm{OH}$ position of apeginin-7-methyl ether through a linker to synthesize desired derivatives using Hugen's 1,3 dipolar cyclo-addition approach. All the synthesized triazolyl hybrids were evaluated against the SKOV3 ovarian cancer cell line. It was demonstrated that that these analogs have the potential to induce apoptosis in human ovarian cancer cell lines. The results facilitate the identification of a lead compound capable of inhibiting colony formation in SKOV3 cells and inducing apoptosis via loss of mitochondrial membrane potential (MMP).

\section{Materials and methods}

Chemistry. In the present study, the reagents and solvents were purchased from Sigma Aldrich; Merck Millipore (Darmstadt, Germany). TLC (0.25 mm silica gel 60 F254; Merck Millipore) plates were used to monitor the reaction progress. Compound purification was performed by column chromatography using silica gel 60-120 mesh. Bruker DPX 410 and DPX 540 NMR instruments were used to record ${ }^{1} \mathrm{H}$ NMR and ${ }^{13} \mathrm{C}$ NMR spectra, TMS as the internal standard and $\mathrm{CDCl}_{3}$ as the solvent. The chemical shifts are expressed in $\mathrm{d}$ ppm and coupling constants in Hertz.

Preparation of propargyl apeginin-7-methylether (compound 2). In a typical procedure, the apigenin-7-methyl ether $(1 \mathrm{mmol})$, propargyl bromide $(1.1 \mathrm{mmol})$ and $\mathrm{K}_{2} \mathrm{CO}_{3}$ (1.5 mmol) were added to a round-bottom flask containing methanol $(10 \mathrm{ml})$. The reaction mixture was then vigorously stirred on a magnetic stirrer at $80^{\circ} \mathrm{C}$ until the initial material had completely disappeared, which was monitored by TLC. Following completion, the reaction mixture was partitioned with EtOAc and water three times. The collected organic layers were concentrated in a vacuum and purified by column chromatography using silica gel (60-120 mesh) and EtOAc: hexane as eluting solvents to produce compound 2 at $98 \%$ yield.

General procedure for the synthesis of triazolyl derivatives $(3 a-g)$. Compound 3 (1 eq) and respective organic azides (1.1 eq) were added to a round bottom flask containing $15 \mathrm{ml}$ of 1:1 water: ethanol mixture, to which $10 \mathrm{~mol} \%$ each of sodium ascorbate and $\mathrm{CuSO}_{4} .5 \mathrm{H}_{2} \mathrm{O}$ was added. The reaction mixture was stirred on a magnetic stirrer at room temperature until its completion. The crude reaction mixture was then partitioned using aqueous ethylacetate. The collected ethylacetate layer was dried over anhydrous magnesium sulphate and subjected to column chromatography using EtOAc: hexane as eluting solvents to produce the pure desired products (3a-g) in quantitative yields.

5-hydroxy-2-(4-((1-(2-(hydroxymethyl)benzyl)-1H-1,2,3-triazol4-yl)methoxy)phenyl)-7-methoxy-4H-chromen-4-one (3a). The details of product $3 \mathrm{a}$ were as follows: White crystalline solid, yield: 93\%; 1H NMR (400 MHz, CDCl3) $\delta 7.55$ (d, J=6.3 Hz, 1H), 7.49 (d, J=7.5 Hz, 2H), 7.37 (s, 1H), 7.23-7.17 (m, 3H), 7.01 (d, J=7.4 Hz, 2H), 6.33 (s, 1H), 6.19 (d, J=1.5 Hz, 1H), 6.13 (d, $\mathrm{J}=1.4 \mathrm{~Hz}, 1 \mathrm{H}), 5.16$ (s, 2H), 4.76 (s, 2H), 3.81 (s, 3H). 13C NMR (125 MHz, ) $\delta 182.28,166.02,163.74,161.60,159.47,140.09$, $137.73,136.17,132.36,129.19,127.52,127.24,126.97,125.85$, $125.31,115.31,105.68,104.77,98.01,93.64,63.36,57.74,56.03$.

5-hydroxy-2-(4-((1-(4-hydroxybenzyl)-1H-1,2,3-triazol-4-yl) methoxy)phenyl)-7-methoxy-4H-chromen-4-one (3b). The details of product $3 \mathrm{~b}$ were as follows: White solid, yield 89\%; 1H NMR (400 MHz, CDCl3 ) \& 7.50 (d, J=7.5 Hz, 2H), 7.42-7.31 (m, 3H), 7.02 (d, J=7.6 Hz, 2H), 6.82 (d, J=7.5 Hz, $2 \mathrm{H}), 6.30(\mathrm{~s}, 1 \mathrm{H}), 6.21(\mathrm{~d}, \mathrm{~J}=1.4 \mathrm{~Hz}, 1 \mathrm{H}), 6.13(\mathrm{~d}, \mathrm{~J}=1.4 \mathrm{~Hz}$, 1H), 5.23 (s, 1H), 3.81 (s, 3H); 13C NMR (125 MHz, CDCl3 ) ઈ $182.28,166.02,163.74,161.60,161.27,159.47,136.00,133.10$, $128.4,128.06,127.24,125.3,117.03,115.3,105.68,104.77$, $98.01,93.64,57.74,56.03$.

5-hydroxy-7-methoxy-2-(4-((1-(4-methoxybenzyl)-1H1,2,3-triazol-4-yl)methoxy)phenyl)-4H-chromen-4-one (3c). The details of product $3 \mathrm{c}$ were as follows: White solid, yield: 89\%; 1H NMR (400 MHz, CDCl3 ) $\delta 7.63$ (d, J=7.5 Hz, 2H), 7.41-7.31 (m, 3H), 7.02 (d, J=7.5 Hz, 2H), 6.81 (d, J=7.5 Hz, 2H), 6.27 (s, 1H), 6.19 (d, J=1.4 Hz, 1H), 6.09 (d, J=1.4 Hz, 1H), $5.27(\mathrm{~s}, 1 \mathrm{H}), 3.81(\mathrm{~s}, 3 \mathrm{H}), 3.80(\mathrm{~s}, 3 \mathrm{H})$.

2-(4-((1-(2-fluorobenzyl)-1H-1,2,3-triazol-4-yl)methoxy)phenyl)5-hydroxy-7-methoxy-4H-chromen-4-one $(3 d)$. The details of product 3d were as follows: White solid, yield: 93\%; $1 \mathrm{H} \mathrm{NMR}$ (400 MHz, CDCl3) $\delta 7.56$ (d, J=7.5 Hz, 2H), 7.48 (m, 1H), 7.39 (s, 1H), $7.15(\mathrm{~m}, 1 \mathrm{H}), 7.10(\mathrm{~m}, 1 \mathrm{H}), 7.07-6.97(\mathrm{~m}, 3 \mathrm{H}), 6.52(\mathrm{~s}, 2 \mathrm{H})$, 6.26 (d, J=1.4 Hz, 1H), 6.11 (d, J=1.6 Hz, 1H), 5.18 (s, 2H), 3.81 (s, 3H).

3-((4-((4-(5-hydroxy-7-methoxy-4-oxo-4H-chromen-2-yl) phenoxy)methyl)-1H-1,2,3-triazol-1-yl)methyl)benzonitrile(3e): The details of product $3 \mathrm{e}$ were as follows: Yellowish solid, yield: 93\%; 1H NMR (400 MHz, CDCl3 ) $\delta 7.98$ (m, 1H), 7.92 (d, J=1.5 $\mathrm{Hz}, 1 \mathrm{H}), 7.51$ (d, J=7.5 Hz, 2H), 7.42-7.32 (m, 3H), 7.03 (d, J=7.5 $\mathrm{Hz}, 2 \mathrm{H}), 6.32$ (s, 1H), 6.21 (d, J=1.4 Hz, 1H), 6.14 (d, J=1.4 Hz, 1H), 5.22 (s, 2H), 3.79 (s, 3H).

2-(4-((1-butyl-1H-1,2,3-triazol-4-yl)methoxy)phenyl)-5-hydroxy7-methoxy-4H-chromen-4-one (3f). The details of product $3 \mathrm{f}$ were as follows: Yellow amorphous powder, yield: $93 \% ; 1 \mathrm{H}$ NMR (400 MHz, CDCl3) \& 7.52 (d, J=7.5 Hz, 2H), 7.11 (s, 1H), 7.03 (d, J=7.5 Hz, 2H), 6.30 (s, 1H), 6.25 (d, J=1.4 Hz, 1H), 6.21 (d, J=1.4 Hz, 1H), 5.22 (s, 2H), 3.82 (s, 3H), 2.93 (m, 2H), 1.26-1.37 (m, 4H), 0.91 (t, 3H, J=7.2 Hz).

2-(4-((1-pentyl-1H-1,2,3-triazol-4-yl)methoxy)phenyl)-5 -hydroxy-7-methoxy-4H-chromen-4-one $(3 g)$. The details of product $3 \mathrm{~g}$ were as follows: Yellow amorphous powder, yield: 93\%; ${ }^{1} \mathrm{H}$ NMR $\left(400 \mathrm{MHz}, \mathrm{CDCl}_{3}\right) \delta 7.50(\mathrm{~d}, J=7.4 \mathrm{~Hz}, 2 \mathrm{H})$, 7.09 (s, 1H), 7.03 (d, J=7.4 Hz, 2H), 6.31 (s, 1H), 6.27 (d, J=1.4 $\mathrm{Hz}, 1 \mathrm{H}), 6.22$ (d, J=1.4 Hz, 1H), 5.22 (s, 2H), 3.82 (s, 3H), 2.95 (m, 2H), 1.29-1.38 (m, 6H), 0.92 (t, 3H, J=7.2 Hz).

Antiproliferative assay. The antiproliferation effect of the novel triazole analogs of apigenin-7-methyl ether against three human ovarian cancer cell lines, OVCAR-3, Caov-3, 
and SKOV3, (Type Culture Collection of Chinese Academy of Sciences, Shanghai, China) was investigated with a 3-(4,5-dimethylthiazol-2-yl)-2,5-diphenyltetrazolium bromide (MTT) assay. The cells were cultured at the density of $1 \times 10^{6}$ cells/well in 96-well plates for a time period of $12 \mathrm{~h}$ at $37^{\circ} \mathrm{C}$. The cells were then subsequently treated with $0-200 \mu \mathrm{M}$ doses of the apigenin-7-methyl ether derivatives for $24 \mathrm{~h}$ at $37^{\circ} \mathrm{C}$. Following this, $20 \mu \mathrm{l}$ of MTT solution was added to each well. Prior to the addition of $500 \mu \mathrm{l}$ of DMSO, the medium was completely removed. For solubilizing the MTT formazan crystals, dimethylsulfoxide $(500 \mu \mathrm{l})$ was added. The absorbance at $570 \mathrm{~nm}$ was measured using an ELISA plate reader. As the derivative $3 \mathrm{~d}$ was found to be most active, only this molecule was used for further experimentation.

Colony formation assay. To investigate the effect of the $3 \mathrm{~d}$ derivative on the colony formation potential of SKOV3 cells, the cells were collected at the exponential growth phase and then counted using a hemocytometer. The platting of the cells was performed at 200 cells/well, and the plates were then incubated at $37^{\circ} \mathrm{C}$ for $48 \mathrm{~h}$ to permit the cells to adhere. This was followed by the addition of various concentrations $(0,5$, 10 , and $20 \mu \mathrm{M})$ of $3 \mathrm{~d}$. Following treatment with $3 \mathrm{~d}$, the cells plates were incubated for 6 days at $37^{\circ} \mathrm{C}$. Following 6 days of incubation, the cells were washed with PBS and fixed with methanol. Subsequently, the cells were treated with crystal violet for $30 \mathrm{~min}$ at room temperature and then counted under a light microscope (magnification, x200).

Detection of apoptosis. The SKOV3 cells were seeded at the density of $1 \times 10^{6}$ cells/well in 6 -well plates and then treated with $0,10,20$ and $40 \mu \mathrm{M} 3 \mathrm{~d}$ for the time period of $24 \mathrm{~h}$ at $37^{\circ} \mathrm{C}$. This was immediately followed by 4',6-diamidino-2-phenylindole (DAPI) staining at $25^{\circ} \mathrm{C}$ for $5 \mathrm{~min}$. The cell samples were then examined and images were captured with a fluorescence microscope (magnification, x200). To estimate the apoptotic cell populations, the SKOV3 cells were seeded at a density of $1 \times 10^{6}$ cells/well in 6-well plates and treated with varied concentrations $(0,5,10$, and $20 \mu \mathrm{M})$ of $3 \mathrm{~d}$ for $24 \mathrm{~h}$ at $37^{\circ} \mathrm{C}$. The cells were then collected and washed with PBS. The cells were then incubated with Annexin V/FITC and PI for $15 \mathrm{~min}$ and the apoptotic cell populations were estimated by flow cytometry (BD Biosciences, San Jose, CA, USA) The estimated percentage of cells in each phase of the cell cycle was quantified using WinMDI software v2.0 (Informer Technologies, Inc., Los Angeles, CA, USA).

Determination of ROS and MMP. The SKOV3 cells were seeded at a density of $2 \times 10^{5}$ cells/well in a 6 -well plate and incubated at $37^{\circ} \mathrm{C}$ for $24 \mathrm{~h}$ and treated with $0,5,10$, and $20 \mu \mathrm{M}$ of $3 \mathrm{~d}$ for $24 \mathrm{~h}$ at $37^{\circ} \mathrm{C}$ in $5 \% \mathrm{CO}_{2}$ and $95 \%$ air. Subsequently, the cells from all samples were collected, washed twice PBS and resuspended in $500 \mu \mathrm{l}$ of DCFH-DA $(10 \mu \mathrm{M})$ for ROS estimation and $\mathrm{DiOC}_{6}(1 \mu \mathrm{mol} / \mathrm{l})$ for $\mathrm{MMP}$ at $37^{\circ} \mathrm{C}$ in a dark room for $30 \mathrm{~min}$. The samples were then examined immediately using a flow cytometer and BD FACSuite software v1.0 (BD Biosciences, San Jose, CA, USA).

Western blot analysis. Protein expression was determined by western blot analysis. Briefly, the cells were lysed in a lysis buffer (20 mM HEPES, $350 \mathrm{mM} \mathrm{NaCl}, 20 \%$ glycerol, $1 \%$ Nonidet P 40, $1 \mathrm{mM} \mathrm{MgCl}_{2}, 0.5 \mathrm{mM}$ EDTA, $0.1 \mathrm{mM}$ EGTA, $1 \mathrm{mM}$ DTT, $1 \mathrm{mM}$ PMSF, $2 \mathrm{mM}$ protease inhibitor cocktail and $10 \%$ phosphatase inhibitor cocktail). The proteins present in the cell extracts were quantified using a BCA assay and proteins $(50 \mu \mathrm{g} /$ lane) from each sample were resolved by SDS-PAGE on a $10 \%$ gel. This was followed by transference onto a nitrocellulose membrane. The membrane was then treated with non-fat milk (5\%) in PBS, and then incubated with a suitable primary antibody: B-cell lymphoma 2-associated X protein (Bax; cat. no. sc-6236) and Bcl-2 (cat no. sc-509) purchased from Santa Cruz Biotechnology, Inc. (Dallas, TX, USA) overnight at $4^{\circ} \mathrm{C}$ (dilution 1:1,000), followed by incubation with horseradish peroxidase-conjugated (cat. no. 9003-99-0) and anti-rabbit secondary antibody (cat. no. sc-2372) (dilution 1:1,000) for $1 \mathrm{~h}$ at room temperature. The western blots were then observed in an ECL western blot analysis system (GE Healthcare Life Sciences, Chalfont, UK).

Statistical analysis. The experiments were repeated three times and results are presented as the mean \pm standard deviation. The significance was determined, compared with the untreated control, using one way analysis of variance and Tukey's test with GraphPad prism 7 software (GraphPad Software, Inc., La Jolla, CA, USA). P<0.01 was considered to indicate a statistically significant difference.

\section{Results}

Synthesis of novel triazole analogs of apigenin-7-methyl ether. In the present study, apeginin-7-methylether (compound 1) was isolated from the ethanolic extract of leaves of Aquilaria sinensis. The isolated natural product (compound 1) was subjected to propargylation using propargyl bromide in presence of base $\mathrm{K}_{2} \mathrm{CO}_{3}$ to give compound 2. Compound 2 was then reacted with different substituted organic azides under click chemistry conditions (Fig. 1) to produce desired 1,2,3-triazole products in quantitative yields. In the ${ }^{1} \mathrm{H}$ NMR, products were easily identified by a characteristic singlet for $\mathrm{H}-5$ in the 1,2,3-triazole moiety, which appeared as singlet downfield $(\sim 7.5 \mathrm{ppm})$ with other aromatic protons. All the prepared triazolyl analogs were characterized by ${ }^{1} \mathrm{H}$ NMR, ${ }^{13} \mathrm{CNMR}$ and MS spectroscopic analysis.

Anticancer effects of synthesized derivatives on ovarian cancer cell lines. To investigate the antiproliferative role of synthesized compounds on three human ovarian cancer cell lines (OVCAR-3, Caov-3, and SKOV3), the cells were treated with different concentrations of the synthesized compounds and the $\mathrm{IC}_{50}$ was determined for all compounds (Table I). Compound $3 \mathrm{~d}$ exhibited a potent antiproliferative effect against SKOV3 cells in a dose-dependent manner with an $\mathrm{IC}_{50}$ of $10 \mu \mathrm{M}$ (Fig. 2). In the formazan crystal assay, it was revealed that administering $3 \mathrm{~d}$ to cells reduced the number of formazan crystals in a concentration-dependent manner (Fig. 3). As 3d exhibited highest activity against the SKOV3 cells, this cell line was used for further experimentation.

Compound $3 d$ induces apoptosis in SKOV3 ovarian cancer cells. Following treatment with the different concentrations 
Table I. $\mathrm{IC}_{50}$ values of novel triazole analogs of apigenin-7-methyl against ovarian cancer cell lines, determined using a 3-(4,5-dimethylthiazol-2-yl)-2,5-diphenyltetrazolium bromide assay.

\begin{tabular}{lccc}
\hline Derivative & SKOV3 $(\mu \mathrm{M})$ & OVCAR-3 $(\mu \mathrm{M})$ & Caov-3 $(\mu \mathrm{M})$ \\
\hline 1 & 29 & 30 & 30 \\
2 & 20 & 25 & 20 \\
$3 \mathrm{a}$ & 18 & 20 & 20 \\
$3 \mathrm{~b}$ & 17 & 20 & 20 \\
$3 \mathrm{c}$ & 25 & 30 & 25 \\
$3 \mathrm{~d}$ & 10 & 15 & 20 \\
$3 \mathrm{e}$ & 40 & 40 & 20 \\
$3 \mathrm{f}$ & 40 & 30 & 30 \\
$3 \mathrm{~g}$ & 40 & 40 & 25 \\
\hline
\end{tabular}

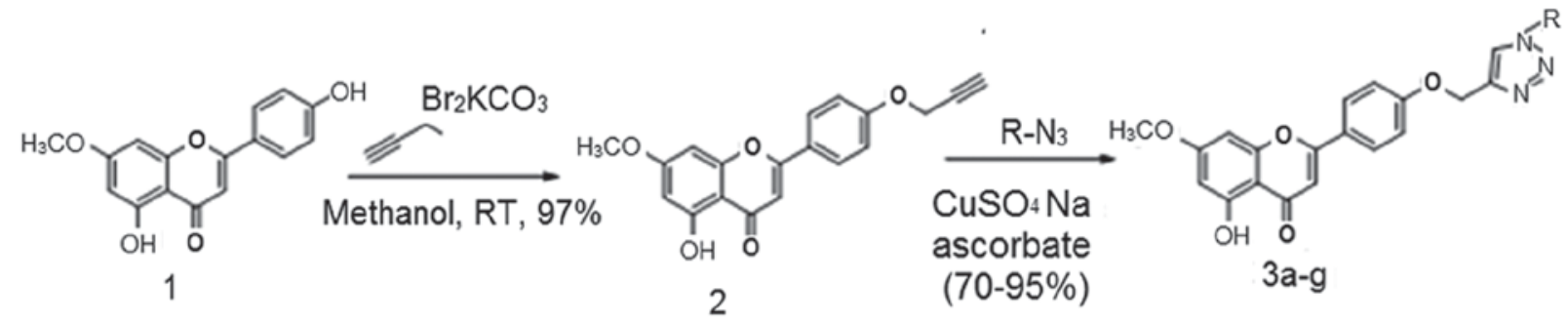<smiles>[R]=C=CCc1ccc(CC)c(CC)c1</smiles>

$3 a$<smiles>CCc1ccc(OCc2ccc(O)cc2)cc1</smiles>

$3 b$

$3 c$<smiles>CCc1ccccc1F</smiles>

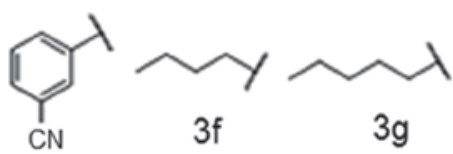

$3 d$

$3 e$

Figure 1. Schematic diagram showing different steps for the synthesis of novel triazole analogs of apigenin-7-methyl ether.

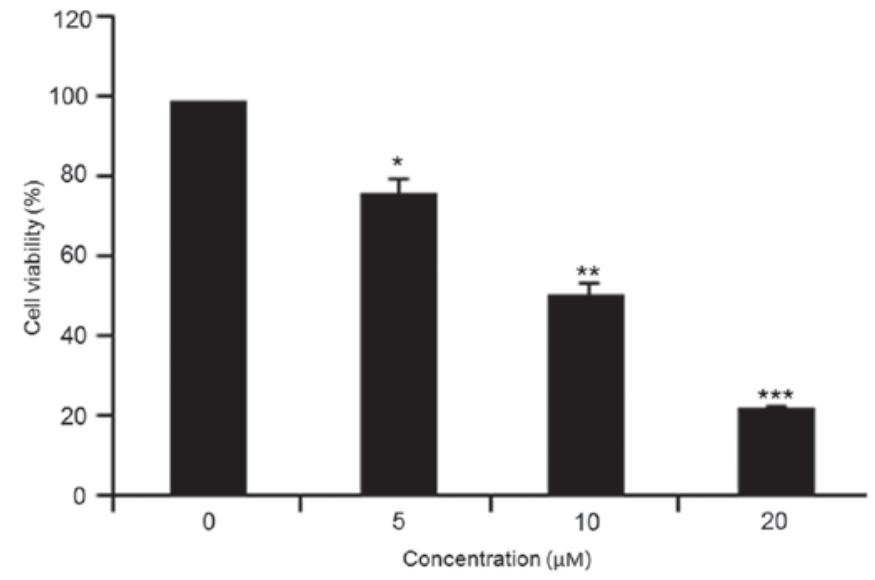

Figure 2. Effect compound 3d on the viability of SKOV3 cells. The experiments were repeated three times and data are presented as the mean \pm standard deviation. $\left(" \mathrm{P}<0.01,{ }^{* *} \mathrm{P}<0.001\right.$ and ${ }^{* * *} \mathrm{P}<0.0001$, vs. untreated control).

of compound 3d, apoptosis was detected by DAPI staining. The results indicated that compound $3 \mathrm{~d}$ caused apoptosis
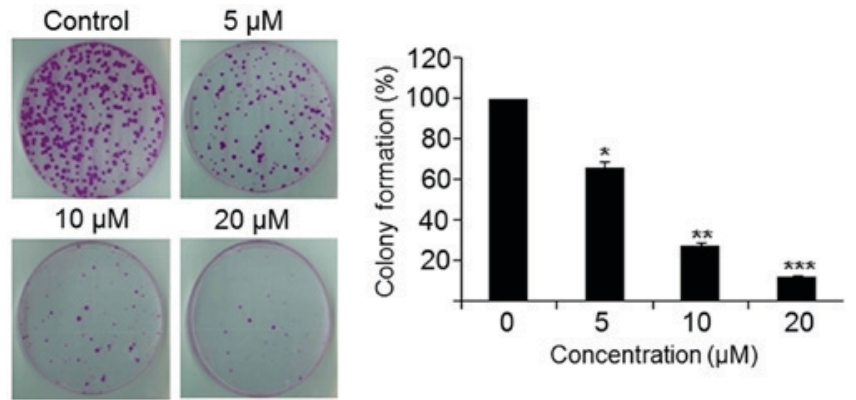

Figure 3. Effect of indicated doses of compound 3d on the colony formation potential of SKOV3 cells. The experiments were repeated three times and data are presented as mean \pm standard deviation $\left({ }^{*} \mathrm{P}<0.01,{ }^{* *} \mathrm{P}<0.001\right.$ and ${ }^{* * * *} \mathrm{P}<0.0001$, vs. untreated control).

in a concentration-dependent manner, as evident from the increased density of white-colored nuclei (Fig. 4). The apoptotic cell populations were further estimated by annexin V/PI staining and it was observed that the apoptotic cell populations increased from $0.05 \%$ in the control to $39.62 \%$ at $20 \mu \mathrm{M}$ 

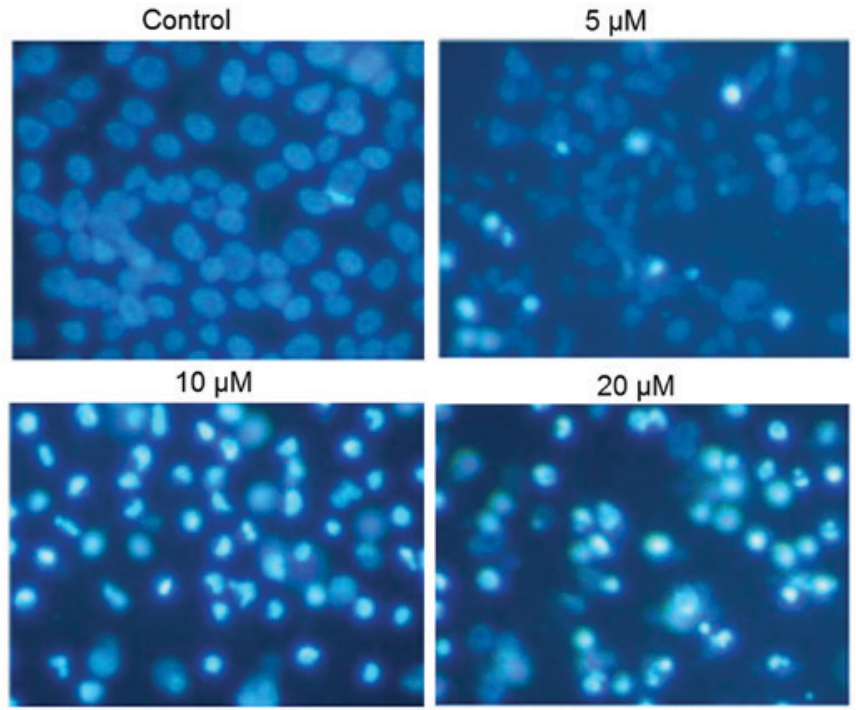

Figure 4. Compound induces apoptosis of SKOV3 cancer cells. Apoptosis was evident from the DAPI staining (magnification, $\mathrm{x} 200$ ). The experiments were repeated three times.

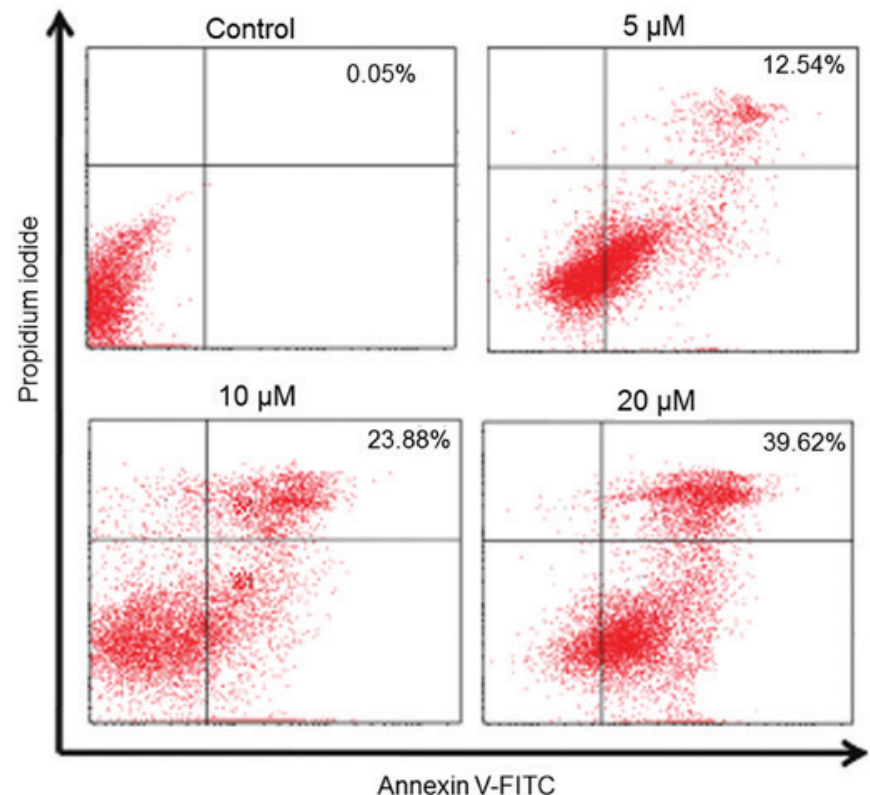

Figure 5. Estimation of apoptotic cell populations at the indicated does of compound $3 \mathrm{~d}$. The experiments were repeated three times.

concentrations of $3 \mathrm{~d}$ (Fig. 5). In addition, this was associated with the increase in the expression of Bax and a decrease in the expression of Bcl-2 (Fig. 6).

Compound 3d triggers ROS activation in SKOV3 ovarian cancer cells. The potential of $3 \mathrm{~d}$ to induce apoptosis, as observed through DAPI staining, indicated that $3 \mathrm{~d}$ may trigger the production of intracellular ROS. Therefore, the present study estimated the ROS level at different concentrations of $3 \mathrm{~d}$ for $48 \mathrm{~h}$. The results showed that the intracellular ROS levels of the treated cells increased up to $255 \%$, compared with the untreated cells (Fig. 7). This result suggested that compound $3 \mathrm{~d}$ is an effective molecule for stimulating the generation of ROS in SKOV3 cells.

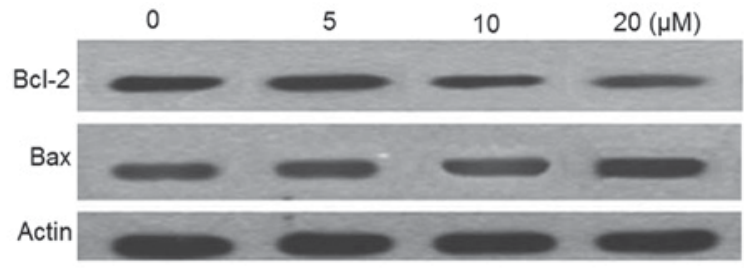

Figure 6. Effect of indicated doses of $3 \mathrm{~d}$ on Bax and Bcl-2 proteins. Protein expression of Bax and Bcl-2 are shown in the western blots. The experiments were repeated three times. Bcl-2, B-cell lymphoma 2; Bax, Bcl-2-associated $\mathrm{x}$ protein.

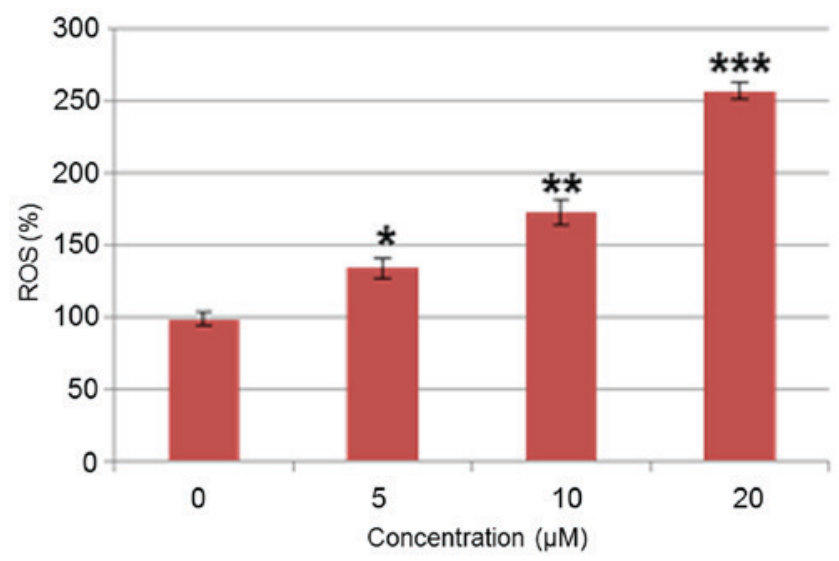

Figure 7. Effect of indicated doses of compound 3d on ROS production. The experiments were repeated three times and data are presented as mean \pm standard deviation $\left({ }^{*} \mathrm{P}<0.01,{ }^{* * *} \mathrm{P}<0.001\right.$ and ${ }^{* * * *} \mathrm{P}<0.0001$, vs. untreated control). ROS, reactive oxygen species.

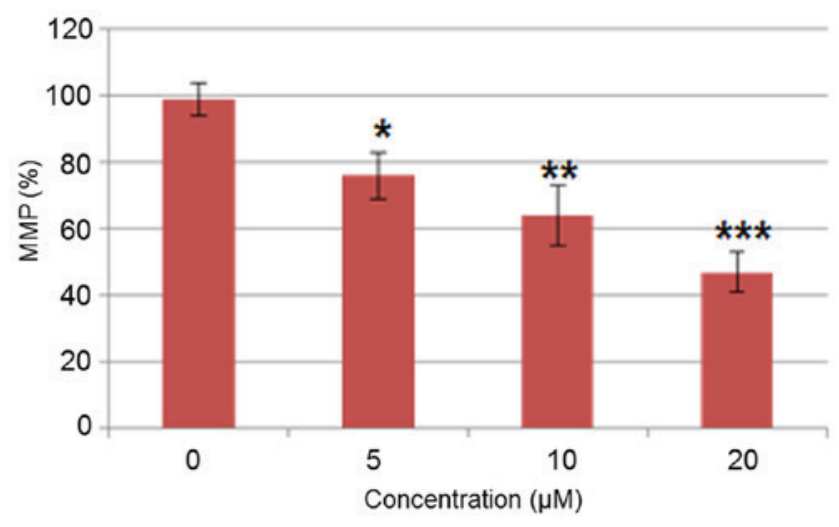

Figure 8. Effect of indicated doses compound 3d on MMP. The experiments were repeated three times and results are presented as the mean \pm standard deviation $\left({ }^{*} \mathrm{P}<0.01,{ }^{* *} \mathrm{P}<0.001\right.$ and ${ }^{* * *} \mathrm{P}<0.0001$, vs. untreated control). MMP, mitochondrial membrane potential.

Compound $3 d$ reduces MMP. The generation of ROS causes mitochondrial mutilation and disrupts the outer mitochondrial potential, ultimately leading to the discharge of death-promoting proteins (16). Therefore, the present study investigated whether compound $3 \mathrm{~d}$ decreased the MMP in the SKOV3 cells administrated with various doses $(0-20 \mu \mathrm{M})$. The compound 3d-administrated SKOV3 cells showed a considerable decrease in MMP in a dose-dependent manner. The MMP decreased up to $63 \%$ at $20 \mu \mathrm{M}$ of compound 3d, compared with that in the untreated control (Fig. 8). 


\section{Discussion}

Of types of gynecological cancer, ovarian cancer is one of the main causes of cancer-associated mortality around the world. Despite preliminary responses to chemotherapy, the tumors consistently relapse $(1,2)$. Apeginin-7-methyl ether is a naturally occurring flavonoid reported to possess several biological activities, including antioxidant, anti-inflammatory and antitumor activities (15). Among these, its anticancer effect has been reported against various human cancer cells. These findings suggest that apigenin is an ideal bioactive scaffold for the synthesis of a series of analogues and examination of their structure-activity associations, and justifies its further investigation. In this context, the present study targeted apeginin-7-methyl ether to synthesize 1,2,3-triazole analogs. All derivatives exhibited potential growth inhibitory effects on the three ovarian cancer cell lines, as evident from the proliferation assay, however $3 \mathrm{~d}$ exhibited the most potent activity against the SKOV3 cancer cell line. As it has been shown previously, several anticancer drugs trigger antiproliferative effects through the induction of apoptosis $(26,27)$. For example, the anticancer drugs cisplatin, taxol and 5-fluorouracil (28-34) have been shown to activate apoptotic pathways and cause DNA damage (35). To assess whether compound $3 \mathrm{~d}$ triggers apoptosis in SKOV3 cells, the treated cells were subjected to DAPI staining. The results revealed that compound $3 \mathrm{~d}$ induced apoptotic damage in a concentration-dependent manner. In addition to this, it was observed that the compound 3d-treated cells showed that ROS promoted a reduction in MMP (33). Therefore, these results indicated that compound $3 \mathrm{~d}$ may trigger apoptosis by the accretion of intracellular ROS and lessening of MMP. These results are well supported by earlier studies wherein a number of anticancer drugs have been shown to cause cancer cell death partly by the generation of high levels of ROS (35). In addition, the role of mitochondria in ROS is key (36). For example, capsaicin disrupts MMP and modulates oxidative stress, resulting in apoptosis of pancreatic cancer cells (37). Therefore, the inhibitory effect of compound $3 \mathrm{~d}$ on ovarian cancer cells may prove beneficial in the treatment and management of ovarian cancer.

In conclusion, a small series of apeginin-7-methylether derived 1,2,3-triazole hybrids were synthesized using an alkyne azide cyclo-addition reaction. All the prepared triazolyl analogs were evaluated against the SKOV3 human ovarian cancer cell line, however, the biological data revealed that compound $3 \mathrm{~d}$ exhibited the lowest $\mathrm{IC}_{50}$ and exerted its anticancer activity through the induction of apoptosis through ROS-mediated alterations in MMP. The present study confirmed that potential anticancer agents can be synthesized from flavonoids.

\section{Acknowledgements}

Not applicable.

\section{Funding}

The current study was supported by The Affiliated Hospital of Taishan Medical University (Taishan, China; grant no. TMU-126/2016).

\section{Availability of data and materials}

The datasets used and/or analyzed during the current study are available from the corresponding author on reasonable request.

\section{Authors' contributions}

YQ, ZD, YY and DM performed all the experiments. FR, HY and $\mathrm{AC}$ collected the materials and provided instrumental suggestion for the present study. AC designed the study.

\section{Ethics approval and consent to participate}

Not applicable.

\section{Petient consent for publication}

Not applicable.

\section{Competing interests}

The authors confirm that they have no competing interests.

\section{References}

1. Leary A, Auclin E, Pautier P, Lhommé C: The PI3K/Akt/mTOR pathway in ovarian cancer: Biological rationale and therapeutic opportunities. Ovarian Cancer-A Clinical and Translational Update: 275-302, 2013.

2. Cancer Genome Atlas Research Network: Integrated genomic analyses of ovarian carcinoma. Nature 474: 609-615, 2011.

3. Altomare DA and Testa JR: Perturbations of the AKT signaling pathway in human cancer. Oncogene 24: 7455-7464, 2005.

4. Engelman JA: Targeting PI3K signalling in cancer: Opportunities, challenges and limitations. Nat Rev Can 9: 550-562, 2009.

5. Hafeez BB, Siddiqui IA, Asim M, Malik A, Afaq F, Adhami VM, Saleem M, Din M and Mukhtar H: A dietary anthocyanidin delphinidin induces apoptosis of human prostate cancer PC3 cells in vitro and in vivo: Involvement of nuclear factor-kappa B signaling. Cancer Res 68: 8564-8572, 2008.

6. Hafeez BB, Fischer JW, Singh A, Zhong W, Mustafa A, Meske L, Sheikhani MO and Verma AK: Plumbagin inhibits prostate carcinogenesis in intact and castrated PTEN knockout mice via targeting $\mathrm{PKC} \varepsilon$, Stat 3 , and epithelial-to-mesenchymal transition markers. Cancer Prev Res (Phila) 8: 375-386, 2015.

7. Lall RK, Adhami VM and Mukhtar H: Dietary flavonoid fisetin for cancer prevention and treatment. Mol Nutr Food Res 60: 1396-1405, 2016

8. Gülçin I: Antioxidant activity of caffeic acid (3,4-dihydroxycinnamic acid). Toxicology 217: 213-220, 2006.

9. Cook NC and Samman S: Flavonoids-chemistry, metabolism, cardioprotective effects and dietary sources. J NutBiochem 7: 66-76, 1996.

10. Rice-Evans CA, Miller NJ, Bolwell PG, Bramley PM and Pridham JB: The relative antioxidant activities of plant derived polyphenolic flavonoids. Free Radic Res 22: 375-383, 1995.

11. Kandaswami C, Lee LT, Lee PP, Hwang JJ, Ke FC, Huang YT and Lee MT: The antitumor activities of flavonoids. In vivo 19: 895-909, 2005.

12. Ren W, Qiao Z, Wang H, Zhu L, Zhang L: Flavonoids: Promising anticancer agents. Med Res Rev 23: 519-534, 2003.

13. Ravindranath $\mathrm{MH}$, Muthugounder $\mathrm{S}$, Presser $\mathrm{N}$ and Viswanathan S: Anticancer therapeutic potential of soy isoflavone, genistein. Adv Exp Med Biol 546: 121-165, 2004.

14. Wang HK: The therapeutic potential of flavonoids. Expert Opin Investig Drugs 9: 2103-2119, 2000

15. Nasr Bouzaiene N, Chaabane F, Sassi A, Chekir-Ghedira L and Ghedira K: Effect of apigenin-7-glucoside, genkwanin and naringenin on tyrosinase activity and melanin synthesis in B16F10 melanoma cells. Life Sci 144: 80-85, 2016. 
16. Androutsopoulos VP, Ruparelia K, Arroo RR, Tsatsakis AM and Spandidos DA: CYP1-mediated antiproliferative activity of dietary flavonoids in MDA-MB-468 breast cancer cells, Toxicology 264: 162-170, 2009.

17. Alvarez R, Velázquez S, San-Félix A, Aquaro S, De Clercq E, Perno CF, Karlsson A, Balzarini J and Camarasa MJ: 1,2,3-Triaz ole-[2',5'-bis-O-(tert-butyldimethylsilyl)-beta-D- ribofuranosyl]-3'-s piro-5"-(4"-amino-1",2"-oxathiole 2",2"-dioxide) (TSAO) analogues: synthesis and anti-HIV-1 activity. J Med Chem 37: 4185-4194, 1994.

18. Genin MJ, Allwine DA, Anderson DJ, Barbachyn MR, Emmert DE, Garmon SA, Graber DR, Grega KC, Hester JB, Hutchinson DK, et al: Substituent effects on the antibacterial activity of nitrogen-carbon-linked (azolylphenyl)oxazolidinones with expanded activity against the fastidious gram-negative organisms Haemophilus influenzae and Moraxella catarrhalis. J Med Chem 43: 953-970, 2000.

19. Majeed R, Sangwan PL, Chinthakindi PK, Khan I, Dangroo NA, Thota N, Hamid A, Sharma PR, Saxena AK and Koul S: Synthesis of 3-O-propargylated betulinic acid and its 1,2,3-triazoles as potential apoptotic agents. Eur J Med Chem 63: 782-792, 2013.

20. Mack DJ, Weinrich ML, Vitaku E and Njarðarson JT: Top 200 Brand Name Drugs by US Retail Sales in 2010. J Chem Ed 87: $1348,2010$.

21. Waring MJ: Lipophilicity in drug discovery. Expert Opin Drug Discov 5: 235-248, 2010.

22. Lipinski CA, Lombardo F, Dominy BW and Feeney PJ: Experimental and computational approaches to estimate solubility and permeability in drug discovery and development settings. Adv Drug Deliv Rev 46: 3-26, 2001.

23. Ferreira SB, Sodero AC, Cardoso MF, Lima ES, Kaiser CR Silva FP, Ferreira VF: Synthesis, biological activity, and molecular modeling studies of $1 \mathrm{H}-1,2,3$-triazole derivatives of carbohydrates as alpha-glucosidases inhibitors. J Med Chem 53 2364-2375, 2010.

24. Whiting M, Muldoon J, Lin YC, Silverman SM, Lindstrom W, Olson AJ, Kolb HC, Finn MG, Sharpless KB, Elder JH and Fokin VV: Inhibitors of HIV-1 protease by using in situ click chemistry. Angew Chem Int Ed Engl 45: 1435-1439, 2006.

25. Lauria A, Delisi R, Mingoia F, Terenzi A, Martorana A, Barone G and Almerico AM: 1,2,3-Triazole in heterocyclic compounds, endowed with biological activity, through 1,3-dipolar cycloadditions. Eur J Org Chem 16: 3289-3306, 2014.

26. Sun SY, Hail N Jr and Lotan R: Apoptosis as a novel target for cancer chemoprevention. J Natl Cancer Inst 96: 662-672, 2004.
27. Chiang JH, Yang JS, Ma CY, Yang MD, Huang HY, Hsia TC, Kuo HM, Wu PP, Lee TH and Chung JG: Danthron, an anthraquinone derivative, induces DNA damage and caspase cascades-mediated apoptosis in SNU-1 human gastric cancer cells through mitochondrial permeability transition pores and Bax-triggered pathways. Chem Res Toxicol 24: 20-29, 2011.

28. Maitra R, Porter MA, Huang S and Gilmour BP: Inhibition of NFkappaB by the natural product Withaferin A in cellular models of Cystic Fibrosis inflammation. J Inflamm (Lond) 6: 15, 2009.

29. Hissin PJ and Hilf R: A fluorometric method for determination of oxidized and reduced glutathione in tissues. Anal Biochem 74: 214-226, 1976.

30. Chipuk JE, Bouchier-Hayes L and Green DR: Mitochondrial outer membrane permeabilization during apoptosis: The innocent bystander scenario. Cell Death Differ 13: 1396-1402, 2006.

31. Azuma M, Tamatani T, Ashida Y, Takashima R, Harada K and Sato M: Cisplatin induces apoptosis in oral squamous carcinoma cells by the mitochondria-mediated but not the NF-kappaB-suppressed pathway. Oral Oncol 39: 282-289, 2003.

32. Yoneda K, Yamamoto T and Osaki T: p53- and p21-independent apoptosis of squamous cell carcinoma cells induced by 5 -fluorouracil and radiation. Oral Oncol 34: 529-537, 1998.

33. Abal M, Andreu JM and Barasoain I: Taxanes: Microtubule and centrosome targets, and cell cycle dependent mechanisms of action. Curr Canc Drug Targs 3: 193-203, 2003.

34. Ferreira CG, Epping M, Kruyt FA and Giaccone G: Apoptosis: Target of cancer therapy. Clin Cancer Res 8: 2024-2034, 2002.

35. Malaguarnera L: Implications of apoptosis regulators in tumorigenesis. Cancer Met Rev 23: 367-387, 2004.

36. Ding H, Han C, Guo D, Chin YW, Ding Y, Kinghorn AD and D'Ambrosio SM: Selective induction of apoptosis of human oral cancer cell lines by avocado extracts via a ROS-mediated mechanism. Nutr Cancer 61: 348-356, 2009.

37. Kowaltowski AJ, de Souza-Pinto NC, Castilho RF and Vercesi AE: Mitochondria and reactive oxygen species. Free Radic Biol Med 47: 333-343, 2009.

(i) (3) This work is licensed under a Creative Commons International (CC BY-NC-ND 4.0) License. 